\title{
Vocabulary Learning Assisted with Smart Phone Application
}

\author{
Zhimei Lei \\ Sichuan University of Arts and Science, Dazhou, China
}

\begin{abstract}
Plenty of study has been done about the Mobile Assisted Language Learning (MALL), which still hasn't found its way into the English vocabulary learning. This empirical study aims to explore an effective way of vocabulary learning through the APP of WeChat on smart phones which are prevalently used among college students. 30 students participated in a WeChat group and were given word tests before and after the research respectively. A questionnaire survey was done a month later. The empirical result shows that it is easy for students to accept this new way of learning and most of them could follow the schedule. They have enhanced their self-regulation study ability and are encouraged to explore various methods to improve their study via smart phone Apps.
\end{abstract}

Index Terms - vocabulary learning, WeChat, smart phone

\section{INTRODUCTION}

Smart phone is prevalently used among Chinese university students as it becomes an indispensable part in people's life. It is small in size, portable and powerful in function. It can not only communicate in real time, receive information but most importantly enables people to complete tasks in daily life and work that used to be done on computers. How to apply smart phones in people's learning efficiently is still under research by teachers and educators. As English words learning is difficult for college students, many scholars and teachers at home and abroad have done experimental studies about English words learning with mobile phones. Many of them are proved to be effective. However, with the rapid development of communication technologies, people have deepened their understanding and usage of mobile phones (smart phones) in their life. Smart phones become increasingly important in people's life and study. Thus, it is necessary to study how to enhance the application and improve its efficiency in English words learning. In the past decade, with it people could only send and receive messages or emails when used in words learning, while today, as it is equipped with a lots of Apps, people could download learning material, share webs and so on.

This paper is going to do a study of words learning with WeChat APP on smart phones and try to evaluate the efficiency of smart phones in words leanings and provide opinions for research activities and pedagogical practice in this field.

\section{LITERATURE REVIEW}

For English words learning assisted by smart phones, this paper will review self-regulated learning (SRL), mobile learning and English words learning respectively.

\section{A. Self-regulated Learning}

According to the requirements of China's Education Ministry (2007) for college English teaching, the advanced communication technologies should be applied into teaching and learning. These new trends in teaching reforms encourage students to choose their own learning materials, finding their own way of learning, and gradually develop their self-regulated learning abilities with necessary instructions.

Self-regulated learning generally refers to "learning that is guided by metacognition, strategic action and motivation to learn". Self-regulated describes "a process of taking control of and evaluating one's own learning and behavior"(Butler, D. L. \& Winne, P. H., 1995, p.245). Contrast to teacher-centered traditional learning which always takes place in classrooms, self-regulated learning is student-centered and much more free for students to set what they learn and where they learn. Paul R. Pintrich and Elisabeth V. De Groot (1990) has mentioned three components for self-regulating learning: One is metacognitive strategies for planning, monitoring, and modifying their cognition; the second is students' management and control of their effort on their tasks and the third is the actual cognitive strategies that students use to learn, remember, and understand the material. So learners should be responsible for their planning, monitoring and modifying in the process of self-study. According to Ormrod, Jeanne Ellis (2009) self-regulated learning has its characteristics as self-efficacy, self-monitoring, self-regulation and collaboration between teachers and students. Zimmerman (1989) suggested three stages of self-regulated learning process: preparing, performance control and self-reflection.

As for the application of self-regulated learning in teaching instructions, Zhou, Y. G. \& Sang, Q. S. (2007) has put forward three models. The first one is personal interaction oriented teaching model which emphasizes the equal status 
and opportunity among students and teachers so to improve their learning initiatives. The second is meaning construction oriented teaching model. With the assistance of teachers or friends and necessary equipment, learners participate in learning activities such as group discussion, self-study, self evaluation etc. to further or deepen their understanding or learning. The third one is self-regulated learning oriented teaching model since people hold that success learning depends on learners' ability to regulate their learning strategies and process.

Scott G. and Alison H. (2001) believe that the past decades have seen the transition from in-classroom to out-classroom. In-classroom practice involves literacy instruction, cognitive engagement, and self-assessment. And out-classroom application includes self-access center, Computer Assisted Language Learning (CALL), distance learning, tandem learning, and self-instruction (Sun M, 2013). It is evident that in recent years, more efforts are spared on out-classroom activities.

We have to admit that there are many factors hinder students from improving their self-regulated learning abilities. The dominant one is that students don't have goals or motivations for learning. Improper learning materials and strategies is the second important reason. Even in students' self-regulated learning, teacher plays a role of supporting and scaffolding in it, thus teacher is important and demanding in it. However, teachers are easily to be bounded by the traditional teaching models and their performance assessment rules. (Zhao T.L., 2013)

\section{B. Mobile Learning}

With the development of information and technologies, mobile devices have evoked innovations in educational activities. Mobile phones (smart phones) are gaining more and more importance because they have provided great advantages for people's living, learning and working. Recently, smart phones are less expensive, lighter and more powerful and they have been trying to find its way into language learning. Some schools and universities have done experimental researches with mobile phones in teaching and learning. Even though studies about the use of mobile phones in language learning are recent and limited, results show that they have positive effects on the learning process. A Cyber University in Japan, founded in 2007, has provided online mobile courses with smart phones. They are free to students. Pui Ching Middle School in Hong Kong Special Administrative Region launched teaching programs with smart phones to promote interaction among students and teachers. Shanghai TV University developed a "Mobile English Learning System", through which students get English words test on their phones everyday and answers and explanations the next day. ("The Development of CALL at Home and Abroad" 2015 ). The study of mobile learning has been changing with the development of technologies,

"The early research in relation to the concept of mobile leaning was closely related to devices and the potential for enabling lifelong learning. It soon became clear that rather than focusing on the device, research should be on the mobility of the learner. Mobile assisted language learning characterizes the use of personal, portable devices that enable new ways of learning, emphasizing continuity or spontaneity of access and interaction across different contexts of use." ( Hu Z. N., 2012)

In An Analytic Study of English Vocabulary Learning with Smart Phones, the author (Lei Z. M., 2017) has classified it into four types. They are: "devices study, material study, effectiveness study, and application of software study" (pp138-139). Son Jeong-Bae (2001) has reviewed the CALL research on vocabulary learning and found two important ways of vocabulary learning via computer. One is the development of lexical CALL programs and the other is the use of on-line lexical resource.

With regard to the research of English vocabulary learning with smart phones, researchers have made a lot of attempts to prove the effectiveness of it. Zhang, H. S., Song, W. \& Burston, J. (July 2011) and Glenn Stockwell (June 2010) did get positive conclusions in their experimental studies.

However, most of them have not been put into practical teaching and learning. Particularly, with the quick development of communication technologies and mobile technologies, many of them have become out-of-date even before being put into practice. What's more, there are some limitations about the researches for some reasons or others. First, though many researches about the effectiveness of words learning with mobile phones turn out to be positive, still little has been done about how fast words learning will become and how many words people can learn in a specific time. In other words, the most concerned issue about words learning is not studied yet. Second, much less studies have been done about the materials fit for words learning on smart phones. Should we just move what is on the text book to smart phones or make some new materials? Third, the technologies of smart phones change quickly and the APPs function powerfully. Traditionally people study in classroom while new APPs on smart phones can enable people to study at any place and any time. As much research of CALL has been done about text messages, photos, pictures etc.in the past, exploration of words learning with new Apps is little. As a result, more researches about how to improve students' vocabulary with smart phones needs to be furthered.

\section{Studies of Vocabulary Learning}

The importance of vocabulary learning can not be overemphasized. However, vocabulary learning is difficult for many students. The reasons may include: First, most students memorize English words by the way of reading and writing repeatedly; Second, they don't have techniques to memorize new words; Third, they don't get into good habit of reviewing words regularly; Forth, much less reading of English magazines, books, newspapers, etc. (Ma C. D., 2007).

In order to promote words learning and teaching, we need to have a comprehensive understanding of words learning. 
Two points should be mentioned concerning vocabulary learning. They are: Firstly, the goals of words learning, that is, how much vocabulary do learners need to know? According to the requirements of China's Education Ministry (2007) for college English teaching, the basic requirement is 4795 words and 700 phrases, a higher requirement needs 6395 words and 1200 phrases, and the highest requirement is 7675 words and 1870 words. Among these words, some are high-frequency words and some are low-frequency words. It is evident that the two should not be given equal importance in teaching and learning.

"There is a small group of high-frequency words which are very important because these words cover a very large proportion of the running words in spoken and written texts and occur in all kinds if uses of the language. The high-frequency words of the language are clearly so important that considerable time should be spent on them by teachers and learners. The time spent on them is well justified by their frequency coverage and range. There is a very large group of words that occur very infrequently and cover only a small proportion of any text. Many low-frequency words are proper names." (Nation, I.S.P., 2001)

Teachers should have different teaching strategies with high-frequency and low-frequency vocabulary. According to Nation, I.S.P.( 2001), high-frequency words should get attention over a long-term English program in the form of "direct teaching, direct learning, incidental learning, and planned meetings with the words" (p16.). And for low-frequency words, "teachers should train learners in the use of strategies to deal with such vocabulary including guessing from context clues, using word parts to help remember words, using vocabulary cards and dictionaries". (p20.) Secondly, how can we say learners know a word? Nation, I.S.P.'s (2001) definition has included "its spoken form, written form, word parts, connecting form and meaning, concepts and referents, associations, grammatical functions, collocations, constraints on use and item knowledge and system knowledge" (p23.) When learning words, college students who aim to pass CET4 (College English Test Band 4) pay more attention to the writing form than spoken form, and more to concepts and referents than associations, collocations, etc..

Given the importance of vocabulary learning, the studies of vocabulary can be categorized into two directions. One is about vocabulary learning strategies, the other is learning assisted with technologies. The English vocabulary learning among college students usually involves eight strategies. They are: 1. using dictionaries; 2. taking notes; 3 . writing down words while reading aloud; 4. synonym and antonym; 5. stems and prefixes; 6. homonym and association; 7. context; 8. singing English songs(Li D. \&Zhou X. L., 2007). What's more, there are still many students never using any strategies in their learning. As the technologies advance, more and more researchers turn to modern-technology equipment such as computers, mobile devices, etc. to facilitate vocabulary learning. Previously CALL-based vocabulary learning applications mainly center on multimedia packages, written texts and vocabulary programs (Glenn Stockwell, 2007, cited in Ma \&Kelly, 2006 ). However, technology has changed people's way of living and learning greatly compared to a decade ago. As a result, it is sensible to find an innovative way combined with smart phones to overcome the difficulties in their words learning.

\section{RESEARCH DESIGN}

\section{A. Research Questions}

The ultimate goal of this research is to find out the acceptability of learning with smart phones, that is, how much the students like to learn words with it, and the effectiveness of learning after a short term of practice. And then a questionnaire was conducted to find out how they learn vocabulary with their smart phones and what their attitudes are towards vocabulary learning assisted by smart phones. A short questionnaire involved the following research questions was conducted:

- Do they want to learn English vocabulary with smart phones or not?

-Of papers and smart phones, which would they prefer to use when learning words?

-How do they view vocabulary learning assisted by smart phones?

-How do they learn vocabulary with smart phones?

\section{B. Participants}

A class of 30 students participated in this project. They are freshmen from non-English major. They have to take English lessons twice a week for four terms and all of them have to pass CET 4 (College English Test band 4) during the four years of their college life. It is important for them to promote their vocabulary, improve English level and pass CET 4. It is particularly important for those who want to further their study after graduation.

\section{Design}

This study is designed to adopt WeChat as a tool for learning and communicating the new vocabulary items. WeChat, a free software provided by China mobile, is applied in this empirical studies. The teacher set up a WeChat group and invited all the students into it and chose one student as an online anchor each time to host a discussion or questioning-and-answering program of the new words which are chosen from the CET4 vocabulary books. These words totaled 300 were all high-frequency words chosen by the teacher and presented to the students in advance. Students should prepare 20 words for every two days according to the requirements of teacher. And at a fixed time-from 20:00 o'clock to 20:30 for every two days, the teacher would randomly choose one student to host the discussion. For the 
word teacher gave includes the spelling and explanation in both Chinese and English, the collocations if any, examples, etc. , students could make sentences or provide Chinese sentences for others to translate it, or seek pronunciations and explanations of those words. Students could voice or type their answers. The experiment has lasted for a month and the learners were asked to respond to a questionnaire survey. The first section of the survey covers the learners' personal information and the second section is about the smart phone use with regard to language learning. The third section addresses learners' perception of the smart phone learning experience.

\section{FINDINGS AND DiSCUSSION}

\section{A. Learner's Willingness to Learn Vocabulary with Smart Phones}

In the questionnaire section with regard to willingness to learn with smart phones, 92 percent said yes, while as for the choice between papers and smart phones, 54 percent chose smart phones and 46 chose paper. This may indicate for the one hand the potential of smart phones in the application of learning, and on the other hand learners don't know how to learn English words with smart phones, that is, there is no popular and effective words learning methods or applications with smart phones. As for learners' attitude toward vocabulary learning assisted by smart phones, learners were required to choose one from the five scales $(1=$ strongly disagree, 2 slightly disagree, $3=$ neutral, $4=$ slightly agree, $5=$ strongly agree). The overall response to vocabulary learning assisted by smart phones was significantly positive. The majority of the learners favored smart phones for vocabulary learning with average scores of 3.9. This indicates that learners have strong desire to use this new mode of vocabulary learning. All these findings prove that the learners' overall attitude toward this new mode of vocabulary learning is positive. These results show they look forward to new ways of language learning as smart phones but do not know how to do. This presents challenges both to the smart phone soft ware developers who have to take into consideration how to meet the needs of learning for learners of all levels and teachers who have to design learning activities and give them guidance to learn with this new medium of smart phones.

\section{B. Learner's Methods of Vocabulary Learning Assisted with Smart Phones}

In the questionnaire with regard to the methods of vocabulary learning assisted with smart phones, among the four given choices, 65 percent chose learning with vocabulary applications on the smart phones, which indicates the major way of vocabulary learning on phones, and 30 percent chose the way that teacher may send them words through messages or Apps like QQ group or WeChat group regularly. Five percent chose others. However, in the designing of vocabulary learning assisted with smart phones, given the importance of regulating learning, combining the vocabulary learning strategies, the author chose WeChat group to assist vocabulary learning. The learner receives 20 new words from the teacher every two days via the WeChat group and downloads on their smart phones. They may read and learn them at anytime and any places as they like, for example, they can memorize the words when they are on buses or when they are in queue. Due to its portability and accessibility, smart phones create opportunities for them to make use of such fragmented time. During the discussion online in WeChat group, each learner gets them involved in it actively while the teacher should also appear each time and correct the misuses or errors they made when necessary, gave praises to those who have good performance, and even push the live broadcast on when silence appears.

Almost all the participants could participate in the vocabulary learning activity each time and most of them have memorized the given words before the discussion. From the feedback of students, they have increased their vocabulary quickly during the period of experiment and this way of learning is proved to be effective in the steady increase of the words number in 30 days. Fig. 1 has shown 10 of those words chosen from the words list whose correct rate is under 10 before test have increased their correct rate dramatically after the learning activity. However, the words they memorize still were focused on their pronunciation and spelling forms, and seldom concerning the usage. For example, they could easily speak out the meanings of the words but hard to give an explaining of them or make sentences with them, not even make differences between synonyms. It is evident that due to the limitations in traditional learning and teaching methods of vocabulary, students have difficulty in creative learning and using of English vocabulary. For the question how they view this way of learning, some students don't like the way they are forced to answer questions and some even recommend a QQ group of English learning in which they just read after a movie clip passively and don't have to interact with others. In short, this method of vocabulary learning assisted with smart phones is seemingly efficient in expanding vocabulary while not so much in its context using. 


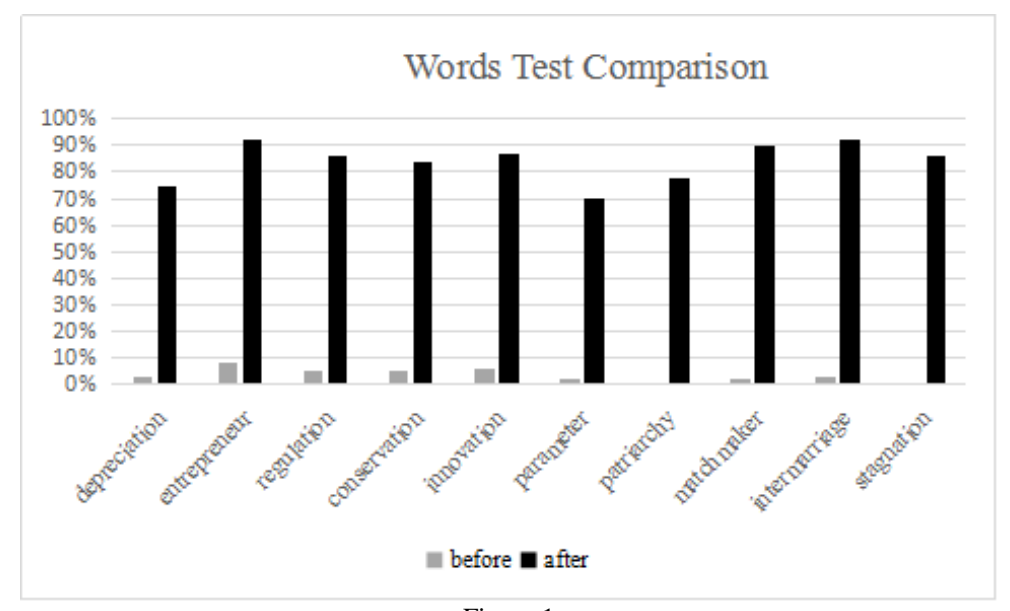

Figure 1

\section{The Advantages of Vocabulary Learning via Smart Phones}

Both in words preparation and online broadcast, learners have their freedom to learn and express. They are given a more relaxed context in which they can follow their own wills without burdens of embarrassment, particularly in the discussion they don't have to express themselves face to face with their classmates, eliminating worries and anxieties that often trouble them when in classroom.

Most learners found this way of words learning as a reminder for self-regulated learning. They think this program can remind them of vocabulary task when they lack the initiative to learn the new words. This program could not only inspire them to study English words autonomously but also encourage them to compete with each other since they get the self-confidence and the sense of achievement if they perform well in the live broadcast.

As non-English major students have a lot of subjects to study and the time they could spend on English learning is much less, smart phone, a portable and light device with powerful functions, was singled out among all the mobile devices to assist with the learning of vocabulary in that it can take best advantage of the learners' fragmented time. In this way, it can not only save their time but increase the learning efficiency.

The reasons why smart phones are chosen in this program are: Firstly, the popularity of smart phones among students makes it possible for learning via smart phone. In addition to communication, smart phone is also a major source of information for most people in the daily life. It becomes an indispensable part in people's life and more and more a learning device. Secondly, smart phone technology has the potential to sustain lifelong education which is taking place and will be popular in the future with the globalization of economies, cultures, etc. During the information age, people always need to renew their knowledge reservoir and obtain new things that are necessary for their life and work or that can make them keep with the the time. In that case, since school learning is not always accessible to people, self-education becomes an very important way of learning for them. Smart phone can meet the need of lifelong education for its convenience, particularly the using of fragmented time without affecting their normal life and work.

\section{The Deficiencies of Vocabulary Learning via Smart Phones}

Though this experiment shows the effectiveness of vocabulary learning via smart phones in increasing its quantity, a lot of problems are exposed to be solved in the future. Firstly, students have strong willingness to apply smart phones in their vocabulary learning yet they could hardly find any good ways or Apps to support their learning. The most commonly done is memorizing words with some Apps such as Shanbaywords, which provides vocabulary for all levels' English tests, Baicizhan with vivid pictures or animations illustrating meanings of words, and Happy Word Game (Kai Xin Ci Chang) on Hujiang network characterized by a game in which learners need to pass through barriers one after another to unlock more and more difficult words. All these Apps require persistence for a long time, which is usually the weak point for most students. What's more important is that the memory of these words could not last long for they are isolated from the context in which they are used. As a result, these Apps are useful when learners need to enhancing their reading ability while in writing and speaking, they could do little help. Therefore, the vocabulary App developers need consider how to improve and perfect words learning Apps so that it will fundamentally facilitate the learners to master the words.

Secondly, in this experiment the students shows unfamiliarity with this way of learning. The reason is that for them smart phone is more of a communication tool with entertainment functions than a device of learning. 46 percent of students in questionnaire choosing "on paper" instead of "on smart phone" to learn vocabulary is an indication in case of it. This dose not mean the attempt of this practice has no significance, rather teachers should give them guidance to explore functions of smart phones in learning. The problem of how teachers should do is critical. Basically the principles that teachers should follow in designing learning activities should be based on self-regulating learning, mobile learning and vocabulary learning requirements. On the other hand, students should be encouraged to develop self-regulating learning consciousness and to explore new ways of study with smart phones. 


\section{CONCLUSION}

In conclusion, the research findings show that most learners do have a strong willingness in learning via smart phones due to the convenience, portability and accessibility of the smart phones. During the experiment, learners participated in the activity and expanded their vocabulary effectively. What's more, this way of learning is never an isolated activity behind the doors though it does encourage self-regulated learning. Learners have to compete with peer members in discussion, which may put pressure on them and remind them to study regularly. In addition, learners could follow the requirements of this experiment and improve their vocabulary continuously. The evidence from this study suggests the potential application of smart phones in vocabulary learning. However, due to the short time period and deficiencies of the experiment, there is still much room to be improved. Therefore, the findings of the current research provide not only for teachers, educators and software developers information they need in the potential application of the mobile technology but also additional insights into the vocabulary learning via smart phones.

In all, vocabulary learning via smart phones can facilitate English learning to some extent for it takes advantage of more fragmented time and effectively increase students' vocabulary by autonomous learning regularly. This empirical study proves the vitality of vocabulary learning via smart phones, explores the potential of smart phones for lifelong learning and provides perceptions for the research of mobile learning.

\section{ACKNOWLEDGMENTS}

This work was supported by a grant from Sichuan University of Arts and Science: Study of Vocabulary Learning Assisted with Smart Phone Application (2014R0042).

\section{REFERENCES}

[1] Butler, D. L. \& Winne, P. H. (1995). Feedback and self-regulated learning: A theoretical synthesis. Review of Educational Research, 65(3), 245-281.

[2] Glenn Stockwell. ( October 2007). Vocabulary on the Move: Investigating an intelligent mobile phone-based vocabulary tutor. Computer Assisted Language Learning, Vol. 20, No. 4, 365 - 383.

[3] Glenn Stockwell. (June 2010). Using Mobile Phones for Vocabulary Activities: Examining the Effect of the Platform. Language Learning \& Technology. Volume 14, Number 2, 95-110.

[4] Higher Education Office of China's Education Ministry. Notification of College English Teaching Requirements (2007). Retrieved from http://www.doc88.com/p-1314621003892.html (accessed 20/07/2015).

[5] Hu, Z. N. (2012). Vocabulary Learning Assisted by Mobile Phones: Perceptions of Chinese Adult Learners. Journal of Cambridge Studies. volume 8 No.1 .139-154.

[6] Lei, Z. M. (2017). An Analytic Study of English Vocabulary Learning with Smart Phones. Sichuan University of Arts and Science Journal. (6). Vol.27 No.6 137-140.

[7] Li D. \&Zhou X. L. (2007). An Overview of English Vocabulary Learning Strategies in China for the Recent 10 Years. Journal of Mudanjiang University. Volume. 16, No.1, Jan. 96-98.

[8] Ma, C. D. (2007). Discussions of English Vocabulary Learning Strategies. Journal of Southwest University for Nationalities. (12). 144-146.

[9] Nation. I.S.P. (2001). Learning Vocabulary in Another Language. Cambridge: Cambridge University Press.

[10] Ormrod, Jeanne Ellis. (2009). Essentials of Educational Psychology Instructor's Copy, New York: Pearson Education Inc..

[11] Paul R. Pintrich \& Elisabeth V. De Groot. (1990). Motivational and Self-Regulated Learning Components of Classroom Academic Performance. Journal of Educational Psychology. Vol.82, No.1, 33-40.

[12] Scott G.\& Alison H. (June 2001). "Classroom Applications of Research on Self-Regulated Learning". Educational Psychologist. 36 (2): 89-101.

[13] Sun, M. (2013). Online Resource and Learner Autonomy - an Action Research on the Developments of College Students' Learner Autonomy from CALL Perspectives. Ph. D dissertation, Shanghai International Studies University.

[14] Son, J.-B. (2001). CALL and vocabulary learning: A review. English Linguistic Science, 7, 27-35.

[15] The Development of CALL at Home and Abroad (2015). Retrieved from http://old.aieln.com/news/2015/11132.html (accessed 13/01/2015).

[16] Zhang, H. S., Song, W. \& Burston, J. (July 2011). Reexamining the Effectiveness of Vocabulary Learning via Mobile Phones. The Turkish Online Journey of Educational Technology_volume 10 issue 3, 203-214.

[17] Zhao, T. L. \& Tian Y. Q. (2013). A Review of Self-Regulated Learning Models in Western Countries: Implications for China. Modern University Education. (6), 54-60.

[18] Zhou, Y. G. \& Sang, Q. S. (Jan 2007). Summary of the Home and Overseas Research on Independent Learning. Journal of Anhui Institute of Education. Volume 25, No. 1, 100-104.

[19] Zimmerman, Barry J. (1989). "A social cognitive view of self-regulated academic learning". Journal of Educational Psychology. 81(3), 329-339.

Zhimei Lei is a lecturer in Sichuan University of Arts and Science in China since 2002. She obtained her Master degree of linguistics in Chongqing Normal University in 2011 and was a visiting scholar in Eastern Mennonite University in USA in 2014. Her latest published article is A Review Study of English Vocabulary Learning with Smart Phones (2017). Her research interests are language learning and teaching. 